\title{
Pathogenesis of encephalomyocarditis experimental infection in young piglets: a potential animal model to study viral myocarditis
}

\author{
Daniela GELMETTI ${ }^{\mathrm{a} *}$, Alessandra MERONI ${ }^{\mathrm{a}}$, Emiliana BROCCHI ${ }^{\mathrm{a}}$, \\ Frank KOENEN $^{\mathrm{b}}$, Giorgio CAMMARATA ${ }^{\mathrm{c}}$
${ }^{\mathrm{b}}$ Veterinary and Agrochemical Research Centre (CODA), Groeselenberg 99, 1180 Ukkel, Belgium
${ }^{\mathrm{c}}$ Dipartimento di patologia animale, igiene, profilassi e sanità pubblica veterinaria, \\ ${ }^{a}$ Istituto Zooprofilattico Sperimentale Lombardia-Emilia Romagna,Via Celoria 12, 20133 Milano, Italy \\ Università degli Sudi di Milano, Via Celoria 10, 20133 Milano, Italy
}

(Received 13 August 2004; accepted 9 June 2005)

\begin{abstract}
The pathogenesis of encephalomyocarditis (EMC) due to the EMC virus (EMCV) was studied in 24 piglets oro-nasally infected with the field isolate B279/95. Two pigs were kept as negative controls and were euthanised at hour 0 . The remaining 24 were euthanised every $6 \mathrm{~h}$ up to 78-h post infection (hpi). Virus isolation, histological examination and EMCV immunodetection were performed on the spleen, intestine, pancreas, liver, kidneys, heart, lungs, lymph nodes, tonsils and brain. EMCV was isolated at 6-hpi from the intestine and lymph nodes and at 12-hpi from the heart. From 6 to 12-hpi, scattered degenerate myocardiocytes were immunolabelled. Subsequently, myocarditis developed and progressively worsened. Immunopositive reaction in tonsil macrophages, observed in the early stage of infection (6-hpi), suggests that tonsils are the portal of entry, and by mean of wandering macrophages the EMC virus is then distributed through the body. Afterwards, EMCV-B279/95 replicates intensively in the cytoplasm of myocardiocytes and the acute myocarditis is strictly related to the tropism of these cells. Four pigs died spontaneously. In three animals no post mortem lesions or virus were isolated/detected, although all of them showed mild myocarditis. The experimental infection with EMCV B279/95 indicates: (i) the experimental protocol mimics the individual variability observed in natural disease, (ii) tonsils are the portal of entry of infection and the heart is the target organ, (iii) EMCV provides a valuable animal model for comparative studies on progressive viral myocarditis.
\end{abstract}

encephalomyocarditis virus-EMCV / swine / myocarditis / immunohistochemistry

\section{INTRODUCTION}

The encephalomyocarditis virus (EMCV) is an RNA virus belonging to the genus Cardiovirus of the family Picornaviridae [37]. It is ubiquitous in nature and has been isolated from both animals (insects, birds, mammals) and humans [35, 40]. Several studies indicate that EMCV can cause interspecies infections, making it a potential zoonotic agent $[5,13,16,28,30]$. However, most of the evidence of human infection has been indirect, detected from the presence of antibodies. In the 1950's only a few

\footnotetext{
* Corresponding author: daniela.gelmetti@bs.izs.it
} 
documented cases of EMCV infection in humans were associated with fever, neck stiffness, lethargy, delirium and headache [24]. Human cases have been reported in Australia, in an area with a high incidence of EMCV in pigs [15]. An EMCV outbreak in a zoo in the United States, involving multiple animal species, did not result in illness in humans, although a zoo attendant who cared for EMCV infected primates demonstrated a high antibody titer [39]. Advances in xenotransplantation, using pig tissues as a means of overcoming shortage of human tissues/organs [5], has renewed interest in pig-to-human zoonotic viruses.

Of all domestic animals, pigs are the most sensitive to EMCV [40]. Isolates that have caused myocarditis in pigs have been associated with rodent outbreaks $[2,19,30]$. In wild rodents, the natural hosts, the virus usually persists without causing disease [32], whereas infection in laboratory rodents commonly [30] produces fatal encephalitis or myocarditis $[7,9,23,27,33,38]$. In swine, the reported natural infections with EMCV have different epidemiological characteristics, probably depending on different EMCV strains which act with different pathogenicity $[1,6]$. EMCV has been recognised as a cause of fatal myocarditis in young piglets or reproductive failure in sows $[1,2,6$, 17, 19, 21, 26, 30]. In Europe, EMCV was first isolated in an outbreak of fatal myocarditis in Italy in 1986 [16]. In Greece, EMCV was associated with sudden death in three month-old piglets although there had been no evidence of reproductive failure in that country since 1986 [26]. In Belgium, the virus has been frequently isolated in association with reproductive failure since 1991 [17], EMCV was isolated in Belgium in 1995 from an outbreak of fatal myocarditis in fattening pigs [19]. In dead pigs the dominant lesion could show focal to multifocal mononuclear myocarditis with myocardial necrosis [1, 2, 21]. The present paper was aimed at providing additional information of the pathogenesis of a Belgian isolate of EMCV in different organs in experimentally infected piglets.

\section{MATERIALS AND METHODS}

\subsection{Virus: origin, antigenic and molecular profile}

EMC virus B279/95 was isolated during an outbreak of fatal myocarditis in fattening pigs in Belgium in 1995. A previous experiment had shown that the virus was virulent for weaning pigs but non-pathogenic for pregnant sows [19]. Sequence analysis showed $[19,20]$ that the viral strain B297/ 95 is clearly related to other EMC viruses isolated in Belgium, Italy and Cyprus but differs from Greek isolates. The antigenic profile of the B279/95 isolate was characterised by using a panel of $40 \mathrm{mAbs}$ identifying 7 antigenic sites, 3 of them involved in virus neutralisation [6]. The reactivity with mAbs was evaluated using a trapping ELISA [18, 29]. Comparative analyses were carried out with approximately 150 isolates responsible for outbreaks of both fatal myocarditis and reproductive failure in pigs in Europe from 1986 to date, and with approximately 50 more isolates from different animal species, collected all over the world over a period of more than 50 years [17]. The overall data demonstrated that the EMC virus is antigenically stable: no correlation between mAbs reactivity and isolate origin (species, geographic distribution and chronology) could be identified. The virus B279/ 95 consistently showed an antigenic profile similar to those of other isolates. Neither the antigenic profiles nor the molecular groupings reflect the pathogenic action of EMCV isolates, which result in reproductive failure or myocarditis $[19,20]$.

\subsection{Experimental design}

Twenty-six Belgian $15 \mathrm{~kg}$ Landrace $x$ Pietrain piglets, which were sero-negative for classical swine fever virus, bovine viral diarrhea virus, African swine fever virus, EMCV and pseudorabies virus, were used in the experiment. All pigs were housed in the same isolation box and were randomly 
numbered to determine their time of euthanisation. Two of them, were kept as negative controls and were euthanised at hour 0 . The remaining 24 pigs were oro-nasally infected with $4 \mathrm{~mL}$ of $10^{3} \mathrm{TCID}_{50} / \mathrm{mL}$ B279/95 EMCV isolate, grown in BHK-21 cells. Every six hours, clinical signs were recorded in the infected group and two piglets were euthanised following a pre determined order. If another pig died it was also examined. The experiment was intended to be stopped at $66 \mathrm{~h}$ and then the remaining pigs were to be monitored. However, only one pig survived until $78 \mathrm{~h}$.

At necropsy, the spleen, intestine, pancreas, liver, kidneys, heart (right and left ventricle; ventricular septum), lung, mesenterial and respiratory lymph node, tonsils and brain samples were collected for viral, histological and immunohistochemical examinations. Virus isolation was also carried out on faeces, urine and blood samples of the euthanised animals.

\subsection{Virus isolation}

Each organ sample was homogenised in minimal essential medium(MEM) $(1 \mathrm{~g} / 10 \mathrm{~mL})$ containing antibiotics and clarified by centrifugation at $10000 \mathrm{~g}$ for $30 \mathrm{~min}$. Blood, urine and faeces were diluted 1:10 in MEM with the addition of $600 \mathrm{mg} / \mathrm{L}$ sulfadoxin, $120 \mathrm{mg} / \mathrm{L}$ trimethoprim and $500000 \mathrm{IU} / \mathrm{L}$ of penicillin and centrifuged at $3000 \mathrm{~g}$ for $10 \mathrm{~min}$. Each harvested supernatant was inoculated on BHK-21 cells, passed 4 times for 3 days each and checked daily for evidence of a cytopatic effect (CPE). The supernatants of cultures showing $\mathrm{CPE}$ were checked using a neutralisation test with specific EMCV-antiserum [18, 19, 36].

\subsection{Histology and immunohistochemistry (IHC)}

The collected organ samples were fixed in $10 \%$ buffered formalin and embedded paraffin.
A total of 2 sets of $4 \mu \mathrm{m}$ thick serial sections from each sample were dewaxed in two changes of xylen and hydrated through graded alcohols. One set was Haematoxylin-Eosin (HE) stained following a standard procedure and the other was immunostained.

Immunostaining was performed using a monoclonal antibody (mAb 3E5) specific for EMCV, recognising a linear epitope of VP1 capsid protein and weakly reacting with VP2 and VP3 capsid proteins (personal communication).

The sections were then immersed in $3 \%$ hydrogen peroxide in distilled water for $30 \mathrm{~min}$ at room temperature and equilibrated with Tris buffered saline (TBS) with $0.5 \%$ Tween 20. Non-specific antibody binding was blocked with normal serum (horse) diluted 1:75 in TBS for $20 \mathrm{~min}$. After that, the sections were immersed in distilled water in a plastic Coplin staining dish and autoclaved in a bain-marie for $5 \mathrm{~min}$ at about $110{ }^{\circ} \mathrm{C}\left(110.8-112.7^{\circ} \mathrm{C}\right.$ at $0.55 \pm 0.05$ bar $)$ in a stainless steel $18 / 10$ pressure cooker (UA106 Lagostina ${ }^{\circledR}$ ) (Personal communication). The sections were then incubated overnight at $+4{ }^{\circ} \mathrm{C}$ with mAb 3 E5 (ammonium sulphate precipitated ascitic fluid containing $10 \mathrm{mg} / \mathrm{mL}$ total proteins) (1:500 dilution). After this first incubation the sections were washed with TBS, incubated a second time with biotinylated-streptavidine peroxidase complex (mouse, Vector) for $30 \mathrm{~min}$, and again rinsed in TBS. 3-3 ${ }^{1}$-diaminobenzidine (DAB; Sigma) was used as a chromogen. After development, the slides were rinsed and counterstained with Mayer Haematoxylin. Immunostaining was performed with appropriate controls. The negative control was the following: heart sections from pigs showing negative EMCV results in ELISA trapping, including those in which primary antibody was replaced by non-immune homologous serum (mouse).

The positive control was the following: heart sections from naturally infected pigs showing positive EMCV results in ELISA trapping, incubated with properly diluted $\mathrm{mAb} 3 \mathrm{E} 5$. 


\section{RESULTS}

\subsection{Clinical signs and gross lesions}

The only clinical sign was sudden death which occurred for the first time between 24 and $30 \mathrm{hpi}$. In total, four swine died at 30 , 54, 66 and 78-hpi respectively. The only discernable gross lesion among infected swine was uneven greyish white discoloration of the heart in 14 out of 16 piglets starting at 30-hpi.

\subsection{Virus isolation}

Five out of 24 pigs tested negative. EMCV was isolated from the heart in 11 out of 24 pigs, beginning at $12 \mathrm{hpi}$. EMCV was inconsistently isolated from several organs in 9 out of 24 pigs (Tab. I). The virus was also isolated from the blood starting at 30-hpi in pig 11, and successively at 48-hpi (pigs 17 and 18), 54-hpi (pigs 19 and 20), 66-hpi (pigs 23 and 24), 78-hpi (pig 26); from faeces at 18-hpi (pig 8), 30-hpi (pigs 11 and 12), 54-hpi (pigs 19 and 20), 66-hpi (pigs 23, 24 and 25).

EMCV was isolated at 6-hpi from the intestinal tract, although in the early phase of the infection (the first $30 \mathrm{hpi}$ ), no clinical signs were noticed. At 30-hpi a pig died and the virus was not isolated from the heart. From 48-hpi most animals were viremic, had heart lesions and EMCV was isolated from most organs.

\subsection{Microscopic lesions}

The histological examination of the liver, spleen, intestine, pancreas, kidneys and brain did not show any specific lesions. Occasionally and probably unrelated to EMC virus infection, catarrhal or interstitial pneumonia was observed with bronchus associated lymphoid tissue hyperplasia. Lymph nodes had different degrees of follicular hyperplasia. Tonsils showed a moderate degree of inflammation, and the crypts contained debris of desquamated epi- thelial cells and some neutrophils (Fig. 1A). The myocardium showed mild hydropic degeneration with focal areas of necrosis and different degrees of interstitial round cell infiltration (plasma cells, lymphocytes, macrophages) and occasionally neutrophils. Degenerate myocardial fibres were hypertrophic, with more eosinophilic and amorphous cytoplasm; elongated nuclei showed clumped chromatin or pyknosis. Right and left ventricles appeared mainly affected. From 6 to $30 \mathrm{hpi}$, the degenerative foci were few, scattered and small; sometimes a slight inflammatory infiltrate was observed. At 42-hpi, myocarditis increased in severity, frequently appearing as multifocal myocarditis (Figs. 1B, 1C and 1D). Three pigs had only focal myocarditis from 60 to 66-hpi.

\subsection{Detection of EMCV by immunohistochemistry}

From 6 to 12-hpi positive staining was observed in the cytoplasm of single myocardial cells and in scattered tonsilar macrophages (Fig. 2A). At 24-hpi, EMCV immunopositive myocardiocytes were observed in 10 out of 18 remaining pigs. The intensity and the distribution of the immunolabelling were in accordance with the severity of histological lesions (Figs. 2B, 2C, and 2D). Immunopositive macrophages were detected in the myocardium, tonsils and lymph nodes. Positive staining was also observed in the endothelial cells of the myocardium (Fig. 2D) and in necrotic debris of the tonsil crypts (Fig. 2A). The liver, spleen, intestine, pancreas, kidney and brain samples were negative.

The negative control pigs (0-hpi) did not show any pathological changes or positive immune staining.

\section{DISCUSSION}

In swine, historical knowledge about the pathogenicity of EMCV indicates the heart as the main target organ $[1,2,4,21,22]$. In 


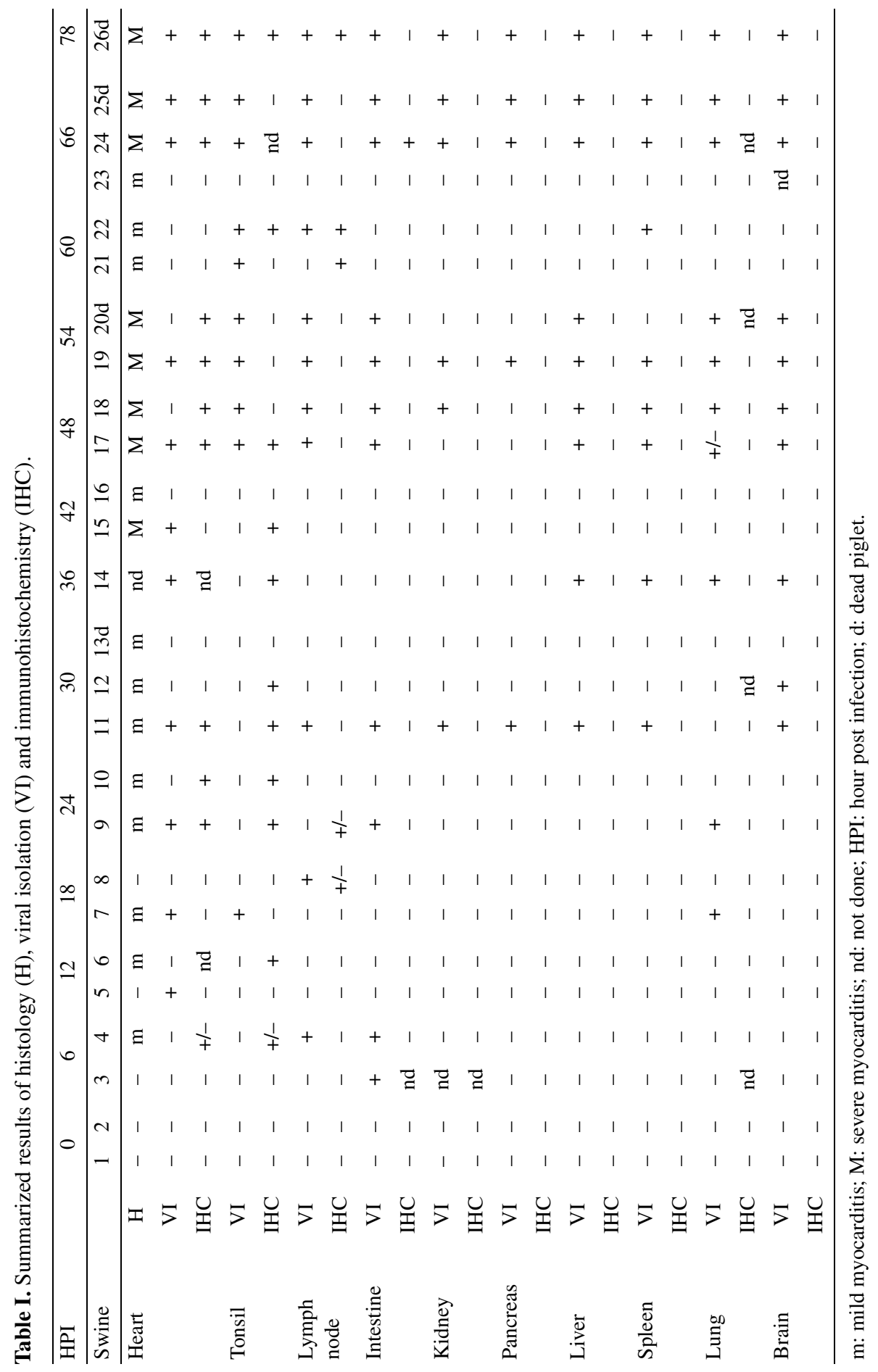



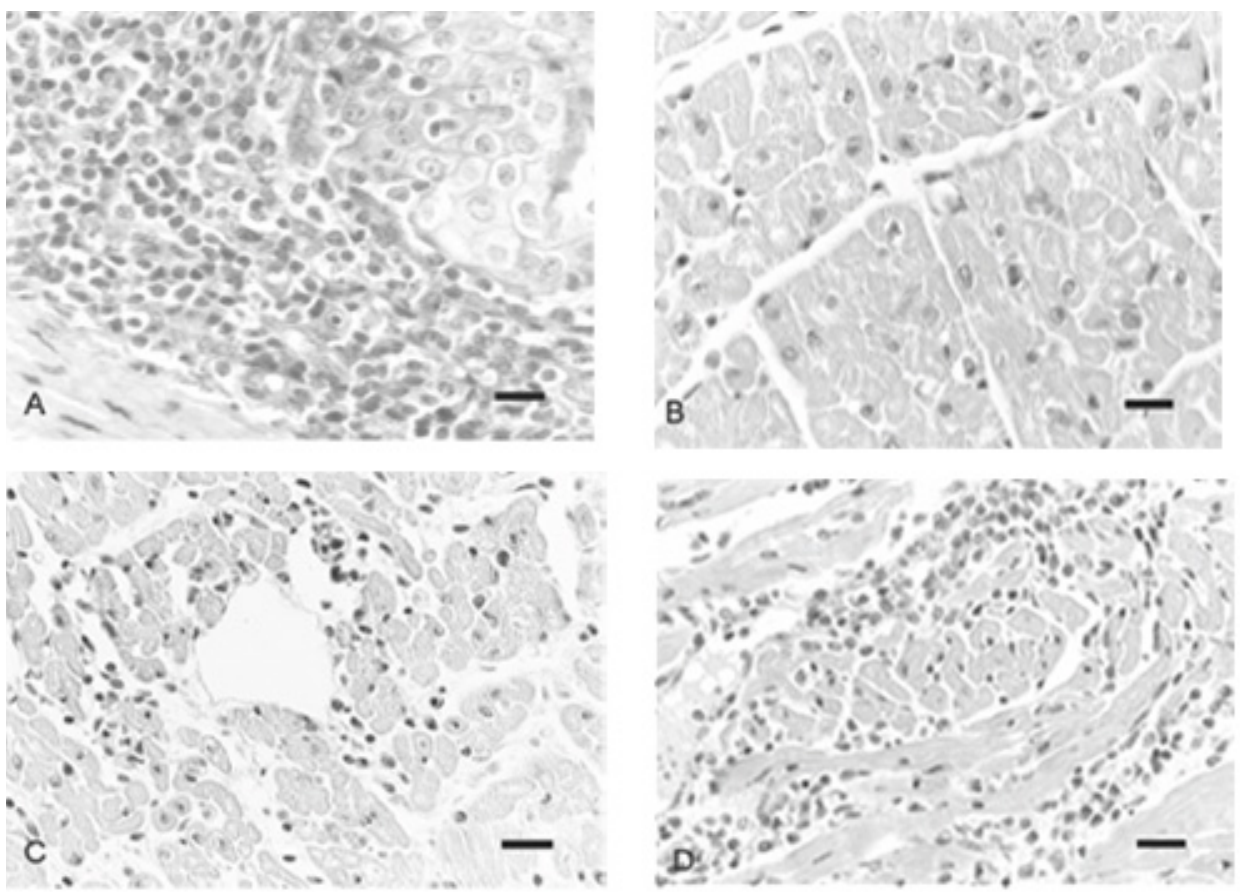

Figure 1. Histology of pig samples at different hours post infection: HE Bar $100 \mu \mathrm{m}$. (A) Tonsil 24-hpi: normal lymphocytic and monocytic-macrophages follicular cell population close to a crypt. (B) Heart 6-hpi: -cross section of apparently normal myocardial cells. (C) Heart 24-hpi: mild lympho-histocytic interstitial myocarditis focused around a small blood vessel. (D) Heart 48-hpi: Severe lympho-histocytic interstitial myocarditis.

laboratory mice and rats, EMCV variants had multiple tropism including acinar pancreas, Langherhan islets, salivary and lachrymal glands, heart and nervous system [7, $8,12,25,32,34,37,40]$. Some authors noticed a similar multiple tropism also in pigs infected with an EMCV isolate from a fatal myocarditis outbreak [25]. Our results confirm that EMCV replicates intensively only in the cytoplasm of myocardiocytes and that viral replication starts in the earlystage (12-24-hpi) of infection before secondary viremia. At this time, myocardium IHC positive staining is scattered and myocardial degenerative changes are focal (Figs. 2B and 2C). In the following hours, viral replication increases and more myocardial cells undergo necrosis, leading to myocarditis. After that, secondary viremia takes place and myocarditis becomes multifocal with abundant inflammatory round cells in the interstitium (Fig. 1D). During the secondary viremic phase (starting at 30-hpi) neither inflammatory nor degenerative changes nor necrosis are observed in organs other than the heart. In the earlier stage of infection (6-24-hpi), when no virus was detected in the circulating blood, EMCV was isolated from the intestine, lymph nodes and lungs of 5 pigs. Since IHC staining and viral isolation from blood samples were negative, we suppose the presence of viral particles could mainly be attributed to the viral intake of macrophages. In conclusion, acute myocarditis is strictly related to EMCV tropism in myocardiocytes. Fairweather et al. [10] pointed out that effective viral replication in the 

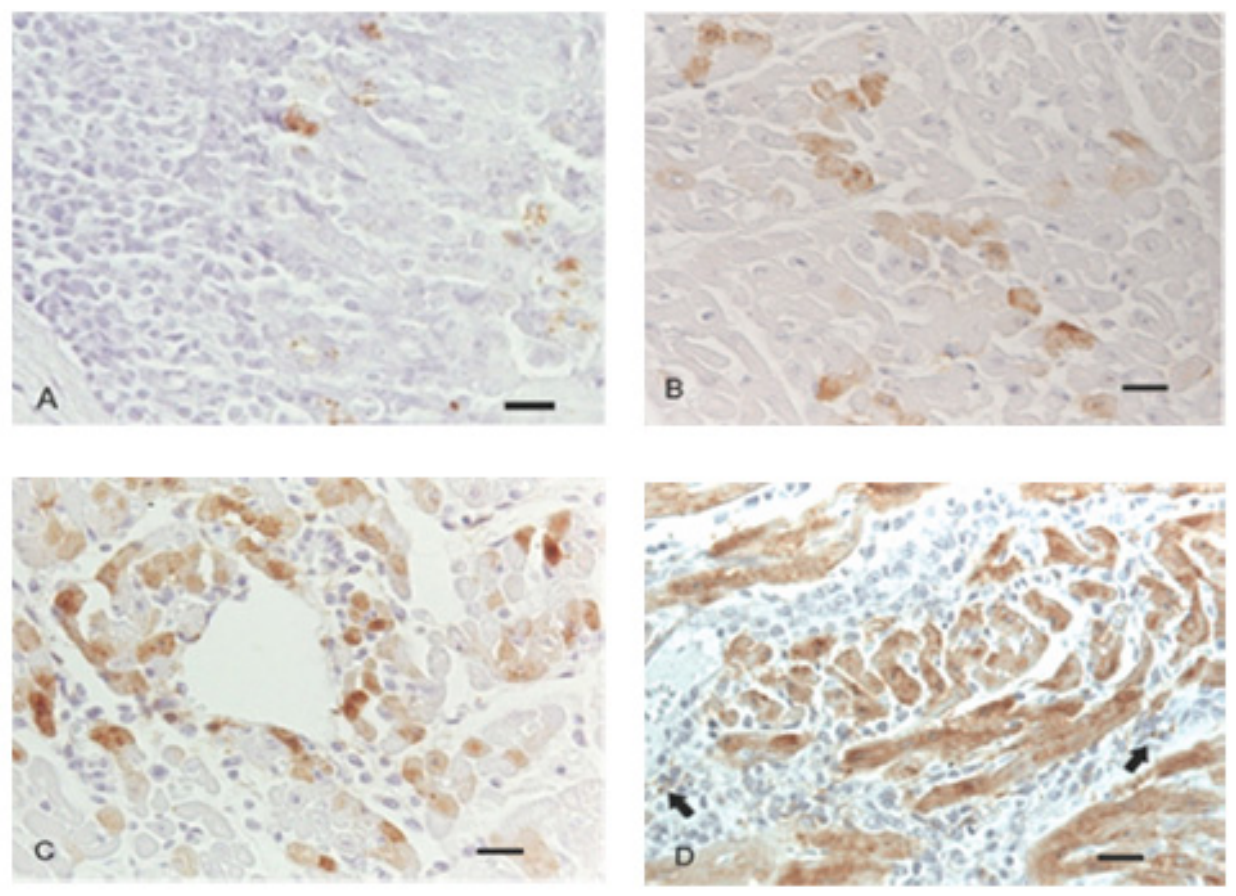

Figure 2. Serial section of the same pig samples shown in Figure 1 immunostained with mAb 3E5. Bar $100 \mu \mathrm{m}$. (A) Tonsil 24-hpi: EMCV immunolocalised in scattered macrophages and in epithelial cellular debris of crypts. (B) Heart 6-hpi: EMCV immunolocalised in the cytoplasm of scattered myocardiocytes without any inflammatory reaction. (C) Heart 24-hpi: EMCV immunolocalised in the cytoplasm of scattered myocardial cells. (D) Heart 48-hpi: EMCV immunolocalised in several myocardial fibres and in scattered endothelial or macrophages cells $(\rightarrow)$.

myocardial cells is clearly necessary for the induction of myocarditis in coxsackievirus and murine cytomegalovirus infection. Other studies demonstrated that, during viral myocarditis, resident cells in the heart, such as endothelial cells and macrophages, in addition to infiltrating cells, could be the source of cytokines. These may trigger antibody production against cardiac myosin, further inducing autoimmune damage, resulting in progressive myocarditis [14, 31].

From 6 to 12-hpi EMCV immunopositive macrophages were detected in the tonsils, suggesting they are important carriers in the spreading of the virus through the body. Tonsils are probably the portal of entry of EMCV, as frequently happens in several other infections such as asymptomatic carriers infected with picornavirus and calici- virus. Tonsils are also the preferred organs of viral persistence [3].

The unsuccessful EMCV detection (VI and IHC) in 3 out of 24 pigs could be attributed to many factors, but, generally, it is chiefly dependent on individual susceptibility to the infectious dose. Similar findings have also been observed in other experiments with high infectious doses and are common in spontaneous outbreaks of EMCV, when only some animals in the herd fall ill $[11,19,21,41]$. The starting myocarditis recorded in three pigs at 60-66-hpi implies that the incubation period was longer or that the infection evolved asymptomatically. This low dose experiment mimics a natural disease that, as observed in natural outbreaks, evolves differently among infected pigs. 
In conclusion, this study indicates that EMCV is picked up by macrophages in the tonsils a few hours after exposure to the virus, and is distributed throughout the body by means of wandering macrophages (primary viremia). In the heart, the target organ, viral replication is followed by myocarditis. Susceptible pigs develop severe myocarditis followed by sudden death, while more resistant pigs develop mild myocarditis and can remain asymptomatic. In resistant pigs, the infection often aborts [5]. In pigs, the variability of clinical signs in viral myocarditis, changing from acute to chronic illness, is in contrast to the uniformity of clinical disease in mice $[7,10]$. Histologically, all myocarditis due to viral replication are similar. Since swine is one of the species biologically closely related to humans, EMC could be a valuable model for comparative studies focusing on the evolution of chronic myocarditis, the progression of viral myocarditis and related immune reaction.

\section{ACKNOWLEDGEMENTS}

Work supported by grant Fair CT99 4146 from the European Union.

\section{REFERENCES}

[1] Acland H.M., Encephalomyocarditis virus infection, in: Pensaert M.B. (Ed.), Virus infections of porcine, Elsevier Science Publishers, Amsterdam, 1989, pp. 259-264.

[2] Acland H.M., Littlejohns I.R., Encephalomyocarditis virus infection of pigs. An outbreak in New South Wales, Aust. Vet. J. 51 (1975) 409-415.

[3] Barker I K, Van Dreumel A.A, Palmer N. Diseases of tonsils, in: Jubb K.V.F., Kennedy P.C., Palmer N. (Eds.), Pathology of domestic animals, Vol. 2, The alimentary system, 4th edition, Academic Press Inc., San Diego, California, 1993, p. 21.

[4] Billinis C., Paschaleri-Papadopoulou E., Anastasiadis G., Psychas V., Vlemmas J., Leontides S., Koumbati M., Kyriakis S.C. Papadopoulos O., A comparative study of the pathogenic properties and transmissibility of a Greek and a Belgian encephalomyocarditis virus (EMCV) for piglets, Vet. Microbiol. 70 (1999) 179-192.

[5] Brewer L.A., Lwamba H.C.M., Murtaugh M.P., Palmenberg A.C., Brown C., Njenga M.K., Porcine encephalomyocarditis virus persists in pig myocardium and infects human myocardial cells, J. Virol. 75 (2001) 1162111629.

[6] Christianson W.T., Kim H.S., Joo H.S. Barnes D.M., Reproductive and neonatal losses associated with possible encephalomyocarditis virus infection in pigs, Vet. Rec. 126 (1990) 54-57.

[7] Craighead J.E., Pathogenicity of the $M$ and $E$ variants of the encephalomyocarditis (EMC) virus. I. Myocardiotropic and neurotrophic properties, Am. J. Pathol. 48 (1966) 333-345.

[8] Craighead J.E., Pathogenicity of the M and E variants of the encephalomyocarditis (EMC) virus. II. Lesions of the pancreas, parotid and lacrimal glands, Am. J. Pathol. 48 (1966) 375386.

[9] Doi K., Ikegami H., Ishii K., Doi C., Yamanouchi Y., Sugano S., Encephalomyocarditis (EMC) infection in the common vole, Microtus arvalis, Lab. Anim. 29 (1995) 180184.

[10] Fairweather D., Kaya Z., Shellam G.R., Lawson C.M., Rose N.R., From infection to autoimmunity, J. Autoimmun. 16(2001) 175186.

[11] Gwathmey J.K., Nakao S., Come P.C., Goad M.E., Serur J.R., Als A.V., Abelmann W.H., An experimental model of acute and subacute viral myocarditis in the pig, J. Am. Coll. Cardiol. 19 (1992) 864-869.

[12] Hirasawa K., Han J.S., Takeda M., Itagaki S., Doi K., Encephalomyocarditis (EMC) virusinduced myocarditis by different virus variants and mouse strains, J. Vet. Med. Sci. 54 (1992) 1125-1129.

[13] Hubbard G.B., Soike K.F., Butler T.M., Carey K.D., Davis H., Butcher W.I., Gauntt C.J., An encephalomyocarditis virus epizootic in a baboon colony, Lab. Anim. Sci. 42 (1992) 233-239.

[14] Huber S.A., Autoimmunity in myocarditis: relevance of animal models, Clin. Immunol. Immunopathol. 83 (1997) 93-102.

[15] Kirkland P.D., Gleeson A.B., Hawkes R.A., Naim H.M., Boughton C.R., Human infection with encephalomyocarditis virus in New South Wales, Med. J. Aust. 151 (1989) 176177.

[16] Knowles N.J., Dickinson N.D., Wilsden G., Carra E., Brocchi E., De Simone F., Molecular analysis of encephalomyocarditis viruses isolated from pigs and rodents in Italy, Virus Res. 57 (1998) 53-62. 
[17] Koenen F., Declercq K., Strobbe R., Isolation of encephalomyocarditis virus in swine with reproductive failure in Belgium, Vlaams Diergeneeskd. Tijdschr. 60 (1991) 113-115.

[18] Koenen F., Vanderhallen H., Papadopoulos O., Billinis C., Paschaleri-Papadopoulou E., Brocchi E., De Simone F., Carra E., Knowles N.J., Comparison of the pathogenic, antigenic and molecular characteristics of two encephalomyocarditis virus (EMCV) isolates from Belgium and Greece, Res. Vet. Sci. 62 (1997) 239-244.

[19] Koenen F., Vanderhallen H., Castryck F., Miry C., Epidemiological, pathogenic and molecular analysis of recent EMC outbreaks in Belgium, J. Vet. Med. B 46 (1999) 217231.

[20] Koenen F., Vanderhallen H., Dickinson N.D., Knowles N.J., Phylogenetic analysis of European encephalomyocarditis viruses: comparison of two genomic regions, Arch. Virol. 144 (1999) 893-903.

[21] Littlejohns I.R., Acland H.M., Encephalomyocarditis virus infection of pigs. 2. Experimental disease, Aust. Vet. J. 51 (1975) 416422.

[22] Marcato P.S., Sarli G., Della Salda L., Barigazzi G., Foni E., Sidoli L., Spinaci M., Ultrastructural study of experimental myocarditis induced by cardiovirus (EMCV-M) in swine, J. Submicrosc. Cytol. Pathol. 24 (1992) 371-379.

[23] Matsuzaki H., Doi K., Mitsouka T., Tutsa T., Onodera T., Experimental encephalomyocarditis virus infection in Mongolian gerbils (Meriones unguiculatus), Vet. Pathol. 26 (1992) 11-17.

[24] Murnane T.G., Viral zoonoses, in: Handbook on zoonoses, section B, vol. 2, CRC Press, Boca Raton, 1981, pp. 137-147.

[25] Papaioannaou N., Billinis C., Psychas V., Papadopoulos O., Vlemmas J., Pathogenesis of EMC virus in pigs during the viraemia phase: histological lesions - immunohistochemical and virological identification of the virus in tissues, J. Comp. Pathol. 129 (2003) 161-168.

[26] Paschaleri-Papadopoulou E., Axitis I., Laspidis C., Encephalomyocarditis of swine in Greece, Vet. Rec. 126 (1990) 364-365.

[27] Petruccelli M.A., Hirasawa K., Takeda M., Itagaki S., Doi K., Cardiac and pancreatic lesions in guineapigs infected with encephalomyocarditis (EMC) virus, Histol. Histopathol. (1991) 167-170.

[28] Reddacliff L.A., Kirkland P.D., Hartley W.J., Reece R.L., Encephalomyocarditis virus infections in an Australian zoo, J. Zoo Wildl. Med. 28 (1997) 153-157.

[29] Samuel A.R., Knowles N.J., Samuel G.D., Crowther J.R., Evaluation of a trapping
ELISA for the differentiation of foot-andmouth disease virus strains using monoclonal antibodies, Biologicals 19 (1991) 299-310.

[30] Seaman J.T., Boulton J.G., Carrigan M.J., Encephalomyocarditis virus disease of pigs associated with a plague of rodents, Aust. Vet. J. 63 (1986) 292-294.

[31] Shioi T., Matsumori A., Sasayama S., Persistent expression of cytokine in the chronic stage of viral myocarditis in mice, Circulation 94 (1996) 2930-2937.

[32] Spyrou V., Maurice H., Billinis C., Papanastassopoulou M., Nielen M., Koenen F., Papadopoulos O., Transmission and pathogenicity of encephalomyocarditis virus among rats, Vet. Res. 35 (2004) 113-122.

[33] Sugawara Y., Hirasawa K., Takeda M., Han J.S., Doi K., Acute infection of encephalomyocarditis (EMC) virus in Syrian hamster, J. Vet. Med. Sci. 53 (1991) 463-468.

[34] Takeda M., Hirasawa K., Doi K., Lesions in central nervous system of $\mathrm{DBA} / 2$ mice infected with the $D$ variant of encephalomyocarditis virus (EMC-D), J. Vet. Med. Sci. 53 (1991) 1013-1017.

[35] Tesh R.B., The prevalence of encephalomyocarditis virus neutralising antibodies among various human populations, Am. J. Trop. Med. Hyg. 27 (1978) 144-149.

[36] Vanderhallen H., Koenen F., Rapid diagnosis of encephalomyocarditis virus infections in pigs using a reverse transcription-polymerase chain reaction, J. Virol. Methods 66 (1997) 83-89.

[37] Van Regenmortel M., Fauquet C., Bishop D., Carstens E., Estes M., Lemon S., Maniloff J., Mayo M., Mc Geoch D., Pringle C., Wickner R., Virus Taxonomy, 7th edition, Academic Press, USA, 2000, pp. 667-669.

[38] Weber U.J., Bock T., Buschard K., Pakkenberg B., Total number and size distribution of motor neurons in the spinal cord of normal and EMC-virus infected mice - a stereological study, J. Anat. 191 (1997) 347-353.

[39] Wells S.K., Gutter A.E., Soike K.F., Baskin G.B., Encephalomyocarditis virus: epizootic in a zoological collection, J. Zoo Wildl. Med. 20 (1989) 291-296.

[40] Zimmerman J.J., Encephalomyocarditis, in: Beran G.W., Steele J.H. (Eds.), Handbook of Zoonoses, Section B Viral, 2nd edition, CRC Press, Boca Raton, 1994, pp. 423-436.

[41] Zimmerman J., Schwartz K., Hill H.T., Meetz M.C., Simonson R., Carlson J.H., Influence of dose and route on transmission of encephalomyocarditis virus to swine, J. Vet. Diagn. Invest. 5 (1993) 317-321. 